\title{
Assessment of hand hygiene facilities and staff compliance in a large tertiary health care facility in northern Nigeria: a cross sectional study
}

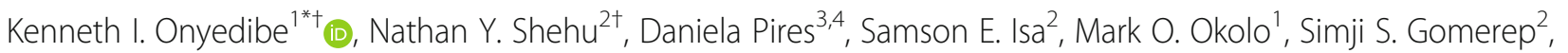
Comfort Ibrahim ${ }^{5}$, Sunday J. Igbanugo ${ }^{6}$, Rachel U. Odesanya ${ }^{6}$, Adebola Olayinka, Daniel Z. Egah ${ }^{1}$ and Didier Pittet ${ }^{3^{*}}$

\begin{abstract}
Background: The burden of healthcare-associated infection (HAl) is 2 to 18 times higher in developing countries. However, few data are available regarding infection prevention and control (IPC) process indicators in these countries. We evaluated hand hygiene $(\mathrm{HH})$ facilities and compliance amongst healthcare workers $(\mathrm{HCW})$ in a 600bed healthcare facility in Northcentral Nigeria providing tertiary care service for a catchment population of about 20 million.

Methods: An in-house facility assessment tool and the World Health Organization (WHO) direct observation method were used to assess the HH facilities and compliance, respectively. Factors associated with good compliance were determined by multivariate analysis.

Results: The facility survey was carried out in all 46 clinical units of the hospital. $72 \%$ of the units had no poster or written policy on $\mathrm{HH}$; $87 \%$ did not have alcohol-based hand rubs; $98 \%$ had at least one handwash sink; $28 \%$ had flowing tap water all day while $72 \%$ utilized cup and bucket; and 58\% had no hand drying facilities. A total of 406 $\mathrm{HH}$ opportunities were observed among $175 \mathrm{HCWs}$. The overall compliance was 31\%, ranging from 18\% among ward attendants to $82 \%$ among medical students. Based on WHO "5 moments" for $\mathrm{HH}$, average compliance was $21 \%$ before patient contact, $23 \%$ before aseptic procedure, $63 \%$ after body fluid exposure risk, $41 \%$ after patient contact and $40 \%$ after contact with patients' surrounding. Being a medical student was independently associated with high HH compliance, adjusted odds ratio: 13.87 (1.70-112.88).
\end{abstract}

Conclusions: Availability of $\mathrm{HH}$ facilities and HCW compliance in a large tertiary hospital in Nigeria is poor. Our findings confirm that HCWs seem more sensitized to their risk of exposure to potential pathogens than to the prevention of HAl cross-transmission. Inadequate HH facilities probably contributed to the poor compliance. Specific measures such as improved facilities, training and monitoring are needed to improve HH compliance.

Keywords: Hand hygiene, Facilities assessment, Compliance, Developing countries, Alcohol-based handrub, Hand sanitizer, WHO multimodal strategy

\footnotetext{
*Correspondence: kenonyedibe@yahoo.com; onyedibek@unijos.edu;

Didier.Pittet@hcuge.ch

Kenneth I Onyedibe and Nathan Y Shehu are first co-authors

${ }^{\dagger}$ Kenneth I. Onyedibe and Nathan Y. Shehu contributed equally to this work.

${ }^{1}$ Department of Medical Microbiology, University of Jos, Jos, Nigeria

${ }^{3}$ Infection Control Programme and WHO Collaborating Centre on Patient

Safety - Infection Control \& Improving Practices, University of Geneva

Hospitals and Faculty of Medicine, Geneva, Switzerland

Full list of author information is available at the end of the article
}

(c) The Author(s). 2020 Open Access This article is distributed under the terms of the Creative Commons Attribution 4.0 International License (http://creativecommons.org/licenses/by/4.0/), which permits unrestricted use, distribution, and reproduction in any medium, provided you give appropriate credit to the original author(s) and the source, provide a link to the Creative Commons license, and indicate if changes were made. The Creative Commons Public Domain Dedication waiver (http://creativecommons.org/publicdomain/zero/1.0/) applies to the data made available in this article, unless otherwise stated. 


\section{Background}

Improving hand hygiene $(\mathrm{HH})$ reduces the transmission of healthcare-associated pathogens and healthcare-associated infections (HAI) [1]. In the United Sates, it has been estimated that HAI incidence ranges from 1.7 to 23.6 per 100 admitted patients accounting for direct annual hospital costs of 28.4 to 33.8 billion U.S. dollars [2] and for approximately 80,000 deaths per year [3]. More importantly, HAI burden is estimated to be up to 18 times higher in developing countries when compared with developed countries [4]. Yet, HAI are frequently preventable through infection prevention and control (IPC) measures, with $\mathrm{HH}$ as key activity $[5,6]$. This reality has led organizations such as the Joint Commission, the World Health Organization (WHO), Centers for Disease Control and Prevention (CDC) and European Center for Disease Prevention (ECDC) to recommend $\mathrm{HH}$ practices and interventions in all healthcare facilities worldwide [ $1,7,8]$. There are two possible ways of performing $\mathrm{HH}$ : hand washing with soap and water or hand rubbing with alcohol-based hand rubs (ABHR) [1, 5-8]. The WHO itemized five key moments when healthcare workers (HCWs) should practice $\mathrm{HH}$ : these are before patient contact, before an aseptic procedure, after bodily fluid exposure risk, after patient contact, and after contact with patient surroundings. Monitoring HCWs compliance with $\mathrm{HH}$ practices is vital for evaluating whether $\mathrm{HH}$ interventions are successful. WHO recommends using a validated methodology for training observers to directly monitor HH using "My five moments for hand hygiene" $[1,9,10]$.

In Nigeria, the overall prevalence of HCAIs ranges between 2.6 and $30.9 \%$, while the cumulative incidence among surgical patients ranges from 5.7 to $48 \%$ [11]. Many fatal infections, such as the nosocomial transmission of endemic Lassa fever in Nigeria and the West African outbreak of Ebola which occurred also in Nigeria might have been curtailed much earlier if IPC measures and $\mathrm{HH}$ facilities were in place and healthcare workers (HCWs) adhered to standard $\mathrm{HH}$ and other IPC practices.

As many factors including inadequate IPC facilities contribute to this problem, there is therefore need to assess IPC facility availability and functionality in Nigerian hospitals. We conducted a survey of availability of $\mathrm{HH}$ facilities and $\mathrm{HH}$ compliance at a tertiary Nigerian hospital while also determining factors associated with compliance.

\section{Methods}

\section{Study design and setting}

The study site is a 600-bed capacity tertiary health care center in Plateau state, North Central Nigeria, serving a population of around 20 million which includes that of the neighboring 8 states as a major referral hospital. Plateau state is located within an area of $26,899 \mathrm{~km}^{2}$. It is located between latitude $80 * 24 \mathrm{~N}$ and longitude $80 * 32$ and
100*38 east. Majority of the inhabitants are either farmers or civil servants. Health care delivery is structured into three tiers: primary, secondary and tertiary health care delivery services and healthcare financing is largely out-ofpocket. Primary and secondary healthcare facilities in the neighboring states refer patients to the study site. The study site has 46 wards and units including an intensive care unit (ICU) and the Special care baby unit. Most wards are designed as open halls with an average capacity of 22- beds. There are a few single-bed private rooms for patients that can afford the fee. The hospital has about 20, 000 annual outpatient medical consultations and over 10, 000 annual admissions. It has 17 clinical departments with specialists: anaesthesia, community medicine, chemical pathology, family medicine, haematology and blood transfusion, histopathology, medical microbiology, obstetrics \& gynaecology, ophthalmology, orthopaedics \& trauma, otorhinolaryngology (ENT), psychiatry, radiology and various sub-specialist surgeons and internists.

There were an estimated 150 nurses, 90 doctors, 130 medical students, 55 nursing students, and 150 attendants that were actively working at the relevant units when the assessment of $\mathrm{HH}$ facilities and compliance were carried out.

Three months prior to this assessment of hand hygiene compliance, $\mathrm{HH}$ sensitization was done by the hospital's infectious diseases physician and medical microbiologist for nurses, doctors, pharmacists and hospital attendants with only about $30 \%$ attendance of HCWs. This consisted of $\mathrm{HH}$ lectures followed by brief question and answer sessions. Before this, there had not been a comprehensive $\mathrm{HH}$ campaign according to WHO multimodal strategy in the hospital.

\section{$\mathrm{HH}$ facilities assessment}

A one-day (20/11/2013) point prevalence survey of available $\mathrm{HH}$ facilities within the tertiary health facility was carried out. This was by the use of a modified Infection Control Self-Assessment Tool [12] that captures multiple parameters and easily adaptable to our setting. Trained study members systematically used the check list to capture relevant data from all clinical wards and other units of the hospital where patients have direct access. Data collected were on availability of tools/items related to water supply and $\mathrm{HH}$ facilities; such as presence of ABHRs; presence and location of sinks, functionality of sinks; presence of hand dryers or disposable towels; availability of water, soap/handwash and availability of written $\mathrm{HH}$ policies, job aids and/or posters. Data were collected by direct observation and HCWs interviews in the various hospital units.

\section{HH compliance}

Phase two was an observational study of HCWs compliance to $\mathrm{HH}$ performed from January 2014 to March 
2014. This was the first audit of $\mathrm{HH}$ compliance ever conducted in the hospital. Members of the Clinical Infection Research Group (CIRG) of the hospital were trained on the WHO direct observation method. This training was conducted by experienced infectious disease physicians and medical microbiologists using a simulation method. We evaluated the level of compliance across different wards and units and among different categories of HCWs. The $\mathrm{HH}$ observations were conducted in the 6 bed-ICU, Medical, Surgical, Pediatrics, Obstetrics and Gynaecology wards, Emergency wards, laboratories and the Pharmacy unit. HH compliance monitoring was conducted and evaluated using the direct observation technique described in the WHO Hand Hygiene Technical Reference Manual (HHTRM) [ 13].

\section{Sample size for compliance assessment}

The sample size was calculated only for $\mathrm{HH}$ compliance assessment. According to the Public health Ontario $\mathrm{HH}$ compliance and observation analysis and observation standards, it is estimated that 56 observation sessions are needed to be collected in order to obtain reliable estimates of compliance in a 100-bed capacity health institution [14]. This translates to a minimum of 336 observations in a 600-bed facility. We observed $406 \mathrm{HH}$ opportunities in the 600-bed institution. Overall compliance was determined by dividing the number of observed hand hygiene actions performed when an opportunity occurs, by the total number of opportunities. Hand hygiene compliance of $>50 \%$ was considered good compliance $[15,16]$.

\section{Data collection and analysis}

Data collected by the trained observers were entered into the standard WHO observation proforma [13]. Observed compliance rates conducted in the different wards and amongst different $\mathrm{HCW}$ categories were analyzed using Epi-Info version 3.5.1 (CDC, Atlanta, Georgia). Chi square test was used to compare differences in proportions and $P$ values of $<0.05$ were considered statistically significant. We used bivariate analysis to identify factors associated with good compliance. Variables with $p$ values $<0.25$ were subjected to a multiple logistic regression analysis model $[17,18]$.

\section{Ethical consideration}

Ethical clearance for the study was obtained from the Research and Ethics Committee of the University Teaching Hospital. All data were securely and confidentially kept.

\section{Results}

For the overall facility assessment, all 46 hospital wards and clinical units were assessed and this is shown in Table 1.

A total of $40(87 \%)$ units did not have ABHRs. Thirtythree units (72\%) had no poster or written policy on hand hygiene. In the 6 units (13\%) where ABHR was available, all were personal pocket-size ABHRs. Forty five (98\%) units had at least one hand washing station. Of these, only $13(28 \%)$ had all day availability of piped water and 32 (72\%) handwashing stations utilized a ladle or cup and bucket (Fig. 1). All sinks were hand operated located by the nurses' station in the open ward and 40 units (87\%) routinely used bar soap, the remaining 13\% either used liquid handwash or just water depending on availability. However, soap or liquid handwash was always available only in 24 units (52\%). Nineteen $(42 \%)$ of the units used multiple-use cloth-towel for hand drying which were changed daily on the average. There were no automated hand dryers or paper towels in any of the units.

A total of $175 \mathrm{HCW}$ s were observed for compliance with $\mathrm{HH}$ practices; these were ward attendants $(n=54,30.9 \%)$; nurses (42, 24\%); medical doctors (27, 15.4\%); nursing students $(21,12 \%)$; pharmacists $(18,10.3 \%)$; and medical students $(13,7.4 \%)$. We observed a total of 406 opportunities for $\mathrm{HH}$; overall compliance was 126/406, 31\% (95\% CI, 27$36)$. The large majority $(103 / 126,82 \%)$ of the $\mathrm{HH}$ actions were performed using handwashing, while only 23/126 (18\%) were through the use of ABHRs. Hand hygiene compliance was $105 / 283,37 \%$ on week-days and $20 / 90,22 \%$ on weekends, $P$ value was 0.017 . Compliance to the 5 moments of $\mathrm{HH}$ varied according to indications for $\mathrm{HH}$; from a highest of $63 \%$ after body fluid exposure risk to $21 \%$ before patient contact, $41 \%$ after patient contact, $40 \%$ after contact with patient environment and $23 \%$ before aseptic procedure (Fig. 2). Stratifying by HCW category, compliance ranged from a maximum of $82 \%$ among medical students to a minimum of $20 \%$ among ward attendants (Fig. 3). Factors associated with hand hygiene compliance are shown in Table 2; as shown, being a medical student was independently associated with good $\mathrm{HH}$ compliance $(p=0.01)$, while working as a ward attendant was independently associated with poor compliance $(p=0.031)$.

\section{Discussion}

Hand hygiene is the most important means of preventing HAI [19]. Over the years, immense efforts have been made at improving $\mathrm{HH}$ compliance worldwide. A major challenge to these efforts remains the availability of functional and accessible $\mathrm{HH}$ facilities. Our study revealed low access to $\mathrm{HH}$ facilities and poor access to today's key cue for action, HH. ABHR was used in only $13 \%$ of the units studied in the hospital, a situation that compels most HCWs to either use soap and water, or forget to wash their hands. This might explain why HCWs in the study performed $\mathrm{HH}$ with ABHR in only $18 \%$ of the HH opportunities observed. Studies previously demonstrated that access to ABHR, associated with multimodal promotion, was critical to improve $\mathrm{HH}$ compliance, in both developed and developing countries healthcare settings [15, 16, 20, 21]. 


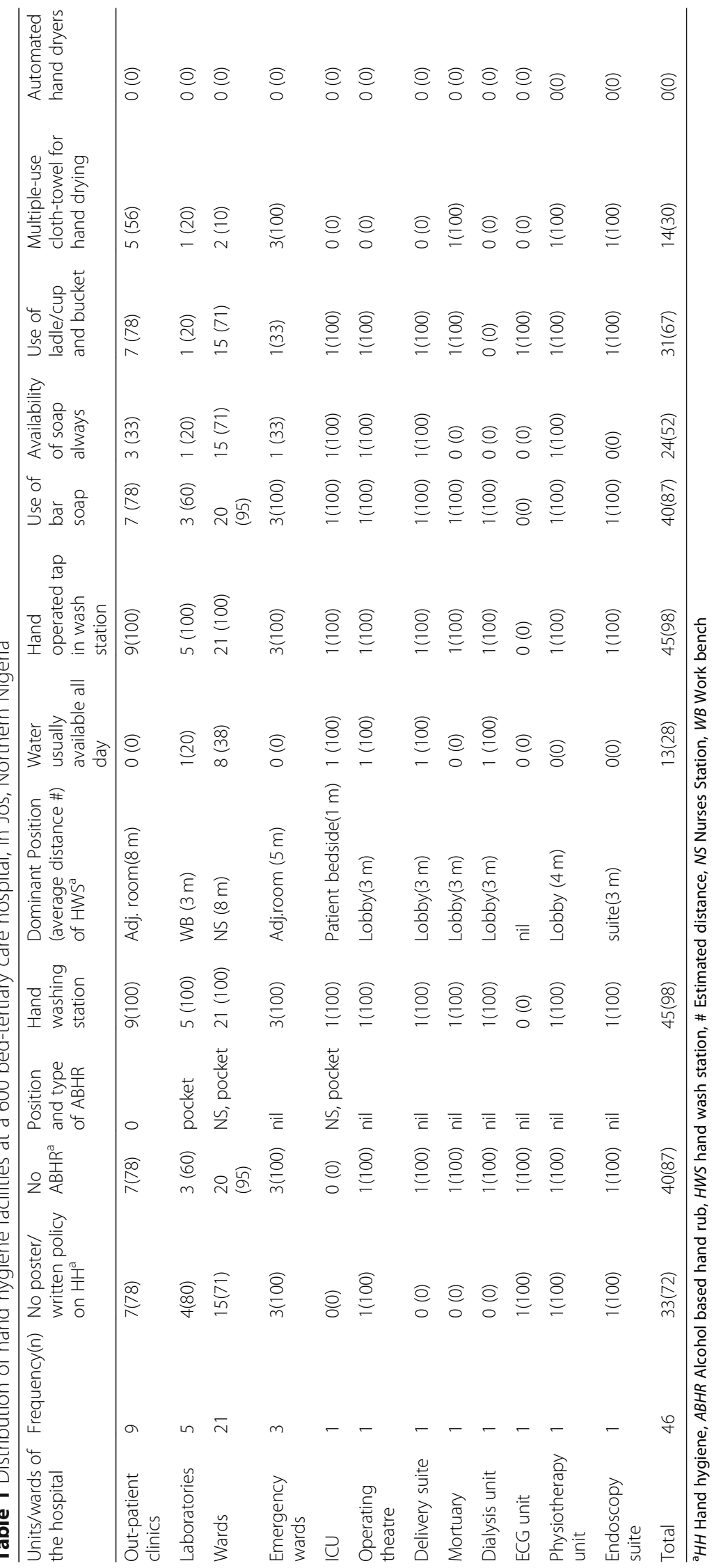



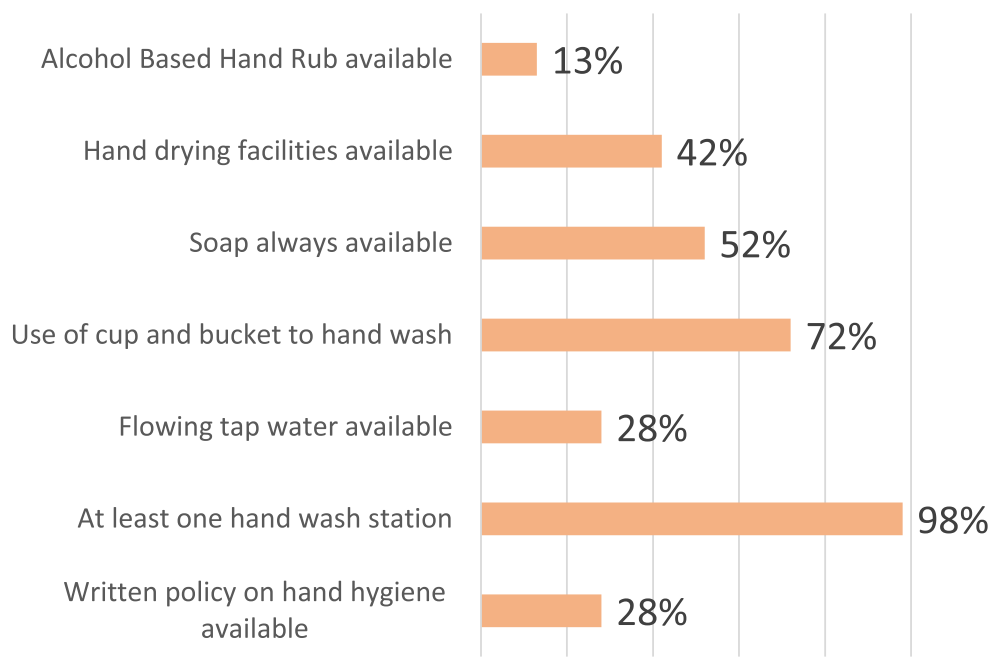

Fig. 1 Proportion of hospital units with available hand hygiene facilities

This study also revealed that availability of handwashing stations was high (98\%). However, only $28 \%$ of the sinks were fully functional with water flowing from their taps all day. This is quite low when compared to reports from a similar study in India with 98\% functional and accessible handwashing sinks [22]. Although our study had a low proportion of functional sinks, a similar Nigerian study found an even lower proportion (14.3\%) [23]. It appears that healthcare funding challenges, poor maintenance attitude and erratic water supply, play a role in the lack of functional sinks in our study, as previously mentioned by Busari et al. [23] Limited access to $\mathrm{HH}$ facilities has been shown to be an important risk factor for poor compliance to $\mathrm{HH}[15,16,20-23]$. In the absence of constant water supply, cleanliness of sinks becomes even more questionable and such sinks may themselves become a source for resistant pathogens and both endemic and epidemic HAIs. Studies identified handwashing sinks as a source of highly fatal multidrugresistant Klebsiella oxytoca and other enterobacteriacea $[24,25]$. The cleanliness of sinks and potential carriage of pathogens was not evaluated in the current study and should be considered in future research.

Furthermore, all the taps in our study were hand operated. Similar findings of hand-operated taps were reported by Busari et al. in Nigeria (100\%) [23], Devnani et al. in India (99.5\%) [22] and Amanzian et al. (93\%) in four Mediterranean countries (Egypt, Morocco, Algeria and Tunisia) [26]. There is an increased risk of contamination of hands and subsequent cross-transmission through hand operated sinks [23-26]. Current recommendations encourage the use of elbow-sensor-operated, or automated

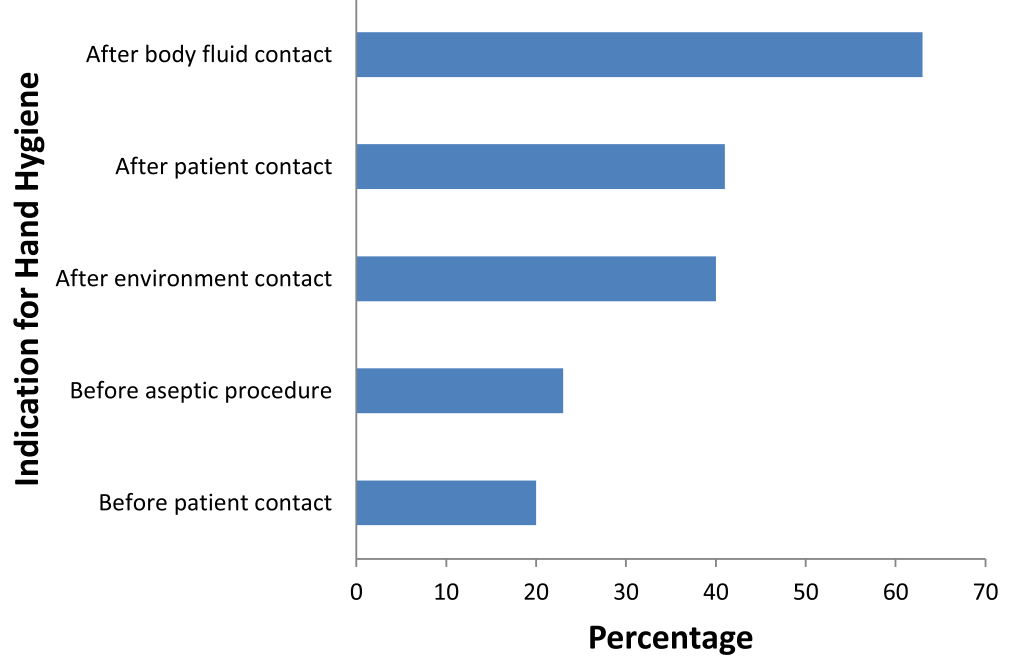

Fig. 2 Compliance with the WHO "5 moments of hand hygiene" 


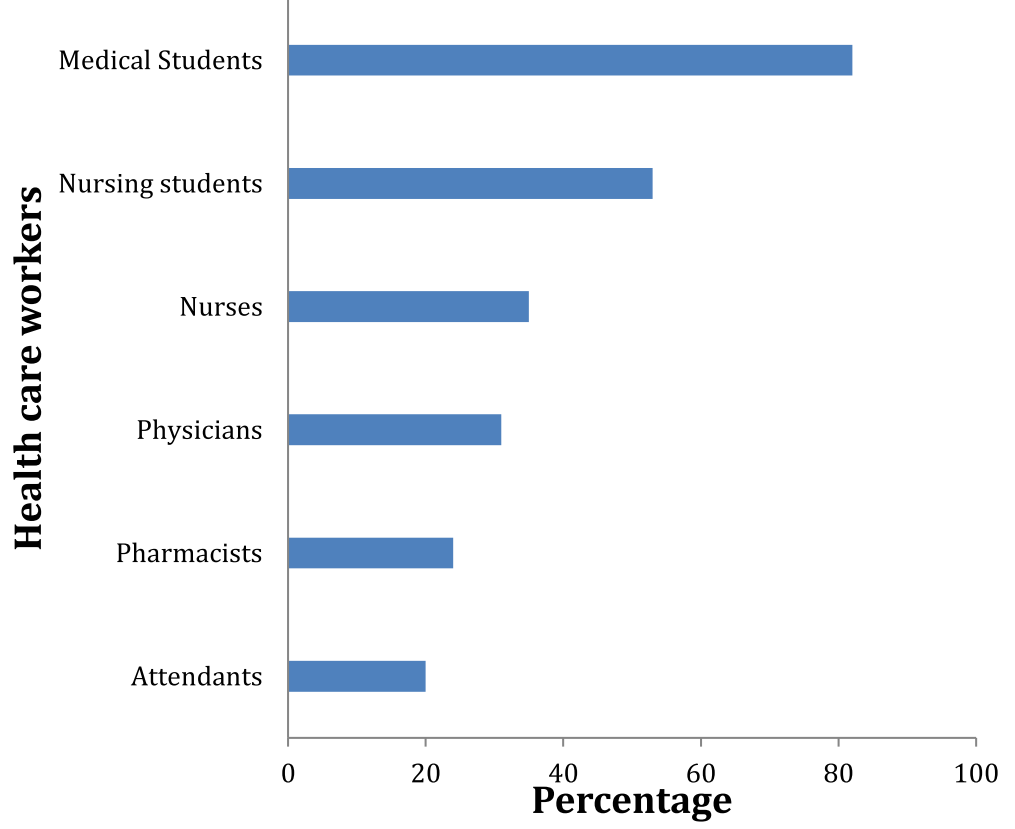

Fig. 3 Compliance with hand hygiene by healthcare worker category in a tertiary hospital, Nigeria

taps for handwashing [27-29]. Moreover, in a large proportion of the units, cups, bowls or a ladle were used to pour water from a bucket to HCWs hands. This practice is challenging when there is no assistant to pour water on hands, further increasing the risk of recontamination of washed hands due to continued contact with the unwashed ladle or cup which had been touched previously with unclean hands. In addition, reusable cloth towels were in use; there were no disposable towels or automated hand dryers in most units as recommended in current guidelines [1, 27-29]. Reusable towels are another potential source of recontamination of HCWs hands and may contribute to spread of HAIs, as reported by other studies [30]. Cross-transmission by reusable towels can mimic 'hand-to-hand' transmission when hands are not washed properly and if the concentration of bacteria on the towel is high enough [31]. The cleanliness of some of the reusable towels, the unavailability of ABHR and the lack of constant water supply could discourage HCWs from performing $\mathrm{HH}$ and might have been the case in this study.

Therefore, the overall $\mathrm{HH}$ compliance observed in the current study (31\%) was not surprising considering the poor availability of $\mathrm{HH}$ facilities. Similar compliance rates were reported from China (30\%) and Kuwait (33.4\%) [32, 33]. Our compliance rate, although lower than acceptable threshold, is higher than previous reports from some other parts of Nigeria (16.7\%), Ethiopia (16.5\%), Mali (8\%) and Indonesia (20\%) [20, 34-36]. Higher rates were reported in Saudi Arabia (50.3\%), southwest Nigeria (55\%) and southeast Nigeria (65.3\%)

Table 2 Factors associated with good compliance with hand hygiene in Jos, 600 bed-tertiary care hospital, Northern Nigeria

\begin{tabular}{lllll}
\hline Variables & Univariate & $P$ value & \multicolumn{2}{l}{$\begin{array}{l}\text { Multivariate } \\
\text { AOR }(95 \% \mathrm{Cl})\end{array}$} \\
\hline Week days (Yes/No) & $2.66(1.18-6.36)$ & 0.017 & $1.70(0.68-4.23)$ & NA \\
Non ICU (vs ICU) & $0.69(0.24-1.86)$ & 0.45 & NA & NA \\
Physicians $^{\mathrm{a}}$ & $0.92(0.39-2.12)$ & 0.84 & $0.61(0.18-2.04)$ & $\mathrm{NA}$ \\
Pharmacists $^{\mathrm{a}}$ & $0.49(0.15-1.40)$ & 0.18 & $\mathrm{NA}$ & $\mathrm{NA}$ \\
Nurses $^{\mathrm{a}}$ & $1.31(0.65-2.65)$ & 0.45 & $13.87(1.70-112.88)$ & 0.01 \\
Medical students $^{\mathrm{a}}$ & $18.90(3.16-417.12)$ & 0.0002 & $2.27(0.80-6.40)$ & 0.12 \\
Nursing students $^{\mathrm{a}}$ & $2.81(1.07-7.91)$ & 0.03 & $0.42(0.19-0.93)$ & 0.031 \\
Attendants $^{\mathrm{a}}$ & $0.31(0.15-0.63)$ & 0.0001 &
\end{tabular}

Good compliance with hand hygiene was defined as compliance greater than $50 \%$

NA Not applicable (Only variables with $p$ values $<0.25$ on univariate were put into multivariate regression model), OR odds ratio, $A O R$ adjusted odds ratio ${ }^{a}$ Compared to other healthcare workers' categories 
[37-39]. The high compliance rate observed in the Southeastern and Southwestern Nigerian studies may be attributed to the positive effect of the interventional programs mentioned in the studies which included systematic $\mathrm{HH}$ training, and the use of $\mathrm{HH}$ posters and other reminders in the hospital facilities. These measures have been shown to improve HH compliance [20, 40, 41].

In our study, $\mathrm{HH}$ compliance was higher among nurses (36\%) than among doctors (31\%). This is consistent with most studies in the literature including a meta-analysis [42]. However, compliance among doctors in our study is higher than reported from an earlier study among doctors in Southern Nigeria (16.7\%) [43] which may suggest that the knowledge and practice of $\mathrm{HH}$ is improving among doctors. The comparatively high compliance rates observed among medical (82\%) and nursing (55\%) students was rather surprising, and has not been reported in previous studies [38, 42]. This is probably due to less workload for the students, a factor known to positively influence $\mathrm{HH}$ compliance. The high compliance amongst students might also be due to close supervision by trainers and to recent curriculum modifications, where IPC and $\mathrm{HH}$ have been introduced as a new module taught to the students.

Contrary to what has been described [44], we found no independent association between working in the ICU with lower $\mathrm{HH}$ compliance rates. The difference with the current study may be due to the comparatively fewer patients in our 6 bed-ICU and the relatively low number of opportunities observed. Pittet et al. had shown that settings with very high number of $\mathrm{HH}$ opportunities (> $60 / \mathrm{h}$ of patient care) would have generally poor compliance rates compared to low ( 0 to $20 \mathrm{HH}$ opportunities) $[44,45]$. We also did not find any independent association between working on weekends and poor $\mathrm{HH}$ compliance. This may be due to fewer $\mathrm{HH}$ observations done on weekends compared to week-days in our study.

Hand hygiene compliance before patient contact was lower $(21 \%)$ than after patient contact (41\%). This trend is similar to that reported in several studies, including a metaanalysis that found lower compliance rates before patient contact (21\%) compared to after patient contact (47\%) [42]. HCWs are more conscious of acquiring infections from patients and the health care environment [46], and our findings confirm that they tend to be more concerned about protecting themselves from acquiring an infection rather than protecting patients. Shobowale et al. in a study in Nigeria, also, found higher compliance after body fluid exposure of about $60 \%$ which is fairly similar to the $63 \%$ in our study. However, they found a comparatively higher compliance rate before aseptic technique [38]. This may be due to the higher availability of $\mathrm{HH}$ facilities at the areas where aseptic procedures were carried out in their study. In a similar study that found a low $\mathrm{HH}$ compliance in Nigeria, the authors suggested that some HCWs assume that wearing gloves reliably replaces $\mathrm{HH}$ [47]. We also found a low $\mathrm{HH}$ compliance after contact with patient surrounding, this is similar to the study by FitzGerald et al. where $\mathrm{HH}$ after contact with patient surrounding appears to be the most commonly missed/neglected moment of $\mathrm{HH}$ [48]. These findings were not unexpected as an overall poor knowledge of $\mathrm{HH}$ in the study setting was previously reported [49].

\section{Conclusions}

$\mathrm{HH}$ facilities were inadequate and $\mathrm{HCW}$ compliance to $\mathrm{HH}$ was low. $\mathrm{HH}$ was performed more after exposure risk to body fluid and patient contact than to other moments and compliance was better during weekdays. Administrative and engineering challenges such as non-availability of piped water, functional handwash stations and poor availability of ABHR may have contributed to the low level of compliance to $\mathrm{HH}$ in this study. Measures to improve $\mathrm{HH}$ compliance such as implementing the WHO multimodal $\mathrm{HH}$ strategy, that includes training, system change with the provision of ABHR and other $\mathrm{HH}$ facilities, and monitoring and feedback of hand hygiene compliance, are needed in our setting and similar settings.

\section{Abbreviations \\ ABHR: alcohol-based hand rubs; CDC : Centers for Disease Control and Prevention; ECDC: European Center for Disease Prevention; HAI : Healthcare- associated infection; HCW: Healthcare workers; HH: Hand hygiene; HHTRM : Hand Hygiene Technical Reference Manual; ICU: Intensive care unit; IPC: Infection prevention and control; WHO: World Health Organization}

\section{Acknowledgements}

We acknowledge the support and contribution of members of the clinical infection research group of the Jos University Teaching Hospital and the University of Geneva Hospitals.

The authors alone are responsible for the views expressed in this article and they do not necessarily represent the views, decisions or policies of the institutions with which they are affiliated. WHO takes no responsibility for the information provided or the views expressed in this paper.

\section{Authors' contributions}

KIO and NYS: Study design, data analysis \& interpretation, manuscript writing \& revision. SEl: Conception, design, data collection, interpretation, manuscript writing and revision. D.Pires: Data interpretation and analysis, manuscript writing and revision. MOO, SG, Cl, Sl, RO: Data collection and manuscript revision. AO, DZE, D.Pittet: Initial Conception, Supervised the design, manuscript writing and manuscript revision. All authors read and approved the final manuscript.

\section{Funding}

This work is supported by the Infection Control Programme and WHO Collaborating Centre on Patient Safety (SPCI/WCC), University of Geneva Hospitals and Faculty of Medicine, Geneva, Switzerland; hand hygiene research activities at the SPCINCC are also supported by the Swiss National Science Foundation (grant no. 32003B_163262).

\section{Availability of data and materials}

The datasets used during the current study are available from the corresponding authors on request.

\section{Ethics approval}

Ethics approval for the study was obtained from the Research and Ethics Committee of the Jos University Teaching Hospital. HREC number: NHREC/ 
13/03/2010. All data were securely and confidentially kept. Consent for participation was not applicable in this study.

\section{Consent for publication}

Not applicable.

\section{Competing interests}

All listed authors declare no financial support, grants, financial interests or consultancy that could lead to conflicts of interest.

Didier Pittet works with WHO in the context of the WHO initiative 'Private Organizations for Patient Safety - Hand Hygiene'.

\section{Author details}

${ }^{1}$ Department of Medical Microbiology, University of Jos, Jos, Nigeria. ${ }^{2}$ Infectious Diseases Unit, Department of Medicine, University of Jos, Jos, Nigeria. ${ }^{3}$ Infection Control Programme and WHO Collaborating Centre on Patient Safety - Infection Control \& Improving Practices, University of Geneva Hospitals and Faculty of Medicine, Geneva, Switzerland. ${ }^{4}$ Department of Infectious Diseases, Centro Hospitalar Lisboa Norte and Faculdade de Medicina da Universidade de Lisboa, Lisbon, Portugal. ${ }^{5}$ Department of Nursing Services, Jos University Teaching Hospital, Jos, Nigeria. ${ }^{6}$ Department of Pharmacy, Jos University Teaching Hospital, Jos, Nigeria. ${ }^{7}$ Department of Medical Microbiology, Ahmadu Bello University, Zaria, Nigeria.

\section{Received: 7 October 2019 Accepted: 3 February 2020} Published online: 11 February 2020

\section{References}

1. World Health Organization. WHO guidelines on hand hygiene in health care. Geneva: World Health Organization; 2009. [22 July 2015]. www.who. int/gpsc/country_work/en/

2. Scott RD. The direct medical costs of healthcare-associated infections in U.S. hospitals and the benefits of prevention. Atlanta: Division of Healthcare Quality Promotion National Center for Preparedness, Detection, and Control of Infectious Diseases Coordinating Center for Infectious Diseases Centers for Disease Control and Prevention; 2009.

3. Klevens RM, Edwards JR, Richards CL Jr, Horan TC, Gaynes RP, Pollock DA, et al. Estimating health care-associated infections and deaths in U.S. hospitals, 2002. Public Health Rep. 2007;122:160-6.

4. Allegranzi B, Nejad SB, Combescure C, Graafmans W, Attar H, Donaldson L, et al. Burden of endemic health-care-associated infection in developing countries: systematic review and meta-analysis. Lancet. 2011;377:228-41.

5. Pittet D, Hugonnet S, Harbarth S, Mourouga P, Sauvan V, Touveneau S, et al. Effectiveness of a hospital-wide programme to improve compliance with hand hygiene. Lancet. 2000;356:1307-12.

6. Allegranzi B, Stewardson AJ, Pittet D. Compliance with hand hygiene best practices. In: Hand hygiene: a handbook for medical professionals, vol. 1. 1st ed. Hoboken: Wiley; 2016. p. 76-84. Doi:978-1-118-84685-8.

7. Centers for Disease Control and Prevention. Hand hygiene in health care settings: hand acknowledgements basics. 2011. [16 July 2015]. www.cdc. gov/handhygiene/Basics.html.

8. National Quality Forum. Safe practice 19: hand hygiene. Safe practices for better healthcare: 2010 update. [July, 2015]. www.qualityforum.org/ Publications/2010/04/Safe_Practices_for_Better_Healthcare_\%E2\%80\%93_2 010_Update.aspx.

9. Sax H, Allegranzi B, Uçkay I, Larson E, Boyce J, Pittet D. 'My five moments for hand hygiene': a user-centred design approach to understand, train, monitor and report hand hygiene. J Hosp Infect. 2007;67:9-21.

10. Lautenbach E. Shojania KG, Duncan BW, McDonald KM, Wachter RM, Markowitz AJ, Making healthcare safer: a critical analysis of patient safety practices. Agency for healthcare research and quality; 2001. [July 17, 2015]. Chapter 12. Practices to improve handwashing compliance. http://archive. ahrq.gov/clinic/ptsafety.

11. Nejad S, Allegranzi B, Syed SB, Ellis B, Didier P. Healthcare associated infection in Africa: a systematic review. Bull World Health Organ. 2011;89: 757-65. https://doi.org/10.2471/BLT.11.088179.

12. Systems for Improved Access to Pharmaceuticals and Services(SIAPS). Infection control self-assessment tool for primary health care facilities. Submitted to the US Agency for International Development by the SIAPS) Program. Arlington: Management Sciences for Health. siapsprogram.org/wp-
content/uploads/2013/01/12-137-ICAT-PCH.FINAL_.pdf. Accessed 27 Nov 2018.

13. World Health Organization \& WHO Patient Safety. Hand hygiene technical reference manual: to be used by health-care workers, trainers and observers of hand hygiene practices. Geneva: World Health Organization; 2009. http:// www.who.int/iris/handle/10665/44196. Accessed 27 Nov 2018

14. Public Health Ontario. Hand hygiene observation and analysis version 1.4. 2009. https://www.publichealthontario.ca > presentation-jcyh-observationanalysis.

15. Owusu-Ofori A, Jennings R, Burgess J, Prasad PA, Acheampong F, Coffin SE. Assessing hand hygiene resources and compliance at a large African teaching hospital. Infect Control Hosp Epidemiol. 2010;31:802-8.

16. Novoa MA, Pi-Sunyer T. SalaM, Molins E, castells X: evaluation of hand hygiene adherence in a tertiary hospital. Am J Infect Control. 2007:35:676-83.

17. Mickey J, Greenland S. A study of the impact of confounder selection criteria on effect estimation. Am J Epidemiol. 1989;129:125-37.

18. Sperandei S. Understanding logistic regression analysis. Biochem Med. 2014; 24(1):12-8. https://doi.org/10.11613/BM.2014.003.

19. Camargo LF, Marra AR, Silva CV, Laselva CR, Moura Junior DF, Cal RG, et al. Low compliance with alcohol gel compared with chlorhexidine for hand hygiene in ICU patients: results of an alcohol gel implementation program. Braz J Infect Dis. 2009;13:330-4.

20. Allegranzi B, Sax H, Bengaly L, Richet H, Minta DK, Chraiti MN, et al. World Health Organization "point G" Project Management Committee. Successful implementation of the World Health Organization hand hygiene improvement strategy in a referral hospital in Mali, Africa. Infect Control Hosp Epidemiol. 2010;31:133-41.

21. Bischoff WE, Reynolds CN, Sessler CN, Edmond MB, Wenzel RP. Handwashing compliance by health care workers: the impact of introducing accessible, alcohol- based hand antiseptic. Arch Intern Med. 2000;160:1017-21.

22. Devnani M, Kumar R, Sharma RK, Gupta AK. A survey of hand washing facilities in the outpatient hospital in India. J Infect Dev Ctries. 2011;5:114-8.

23. Busari OA, Agboola SA, Oyekale OT, Ojo OM, Oje OJ, Oladosun YO. A survey of hand hygiene in a tertiary hospital in Nigeria. TAF Prev Med Bull. 2012;11:571-6.

24. Lowe C, Willey B, O'Shaughnessy A, Lee W, Lum M, Pike K, et al. Outbreak of extended-spectrum $\beta$-lactamase-producing Klebsiella oxytoca infections associated with contaminated handwashing sinks. Emerg Infect Dis. 2012;18:1242-7.

25. Leitner E, Zarfel G, Luxner J, Herzog K, Pekard-Amenitsch S, Hoenigl M, Zollner-Schwetz I. Contaminated Handwashing sinks as the source of a clonal outbreak of KPC-2-producing Klebsiella oxytoca on a hematology Ward. Antimicrob Agents Chemother. 2015;59:714-6.

26. Amazian K, Abdelmoumene T, Sekkat S, Terzaki S, Njah M, Dhidah L, et al. Multi Centre study on hand hygiene facilities and practice in the Mediterranean area: results from the NosoMed network. J Hosp Infect. 2006; 62(3):311-8

27. Boyce J, Pittet D. Guideline for hand hygiene in health-care settings: recommendations of the healthcare infection control practices advisory committee and the HICPAC/SHEA/APIC/IDSA hand hygiene task force. Infect Control Hosp Epidemiol. 2002;23(12, suppl):S3-S40.

28. Pittet D, Allegranzi B, Sax H. Evidence-based model for hand transmission during patient care and the role of improved practices. Lancet Infect Dis. 2006;6(10):641-52

29. Allegranzi B, Pittet D. Role of hand hygiene in healthcare-associated infection prevention. J Hosp Infect. 2009;73(4):305-15.

30. Huang C, Ma W, Stack S. The hygienic efficacy of different hand-drying methods: a review of the evidence. Mayo Clin Proc. 2012;87(8):791-8. https://doi.org/10.1016/j.mayocp.2012.02.019.

31. Bellissimo-Rodrigues F, Pires D, Soule H, Gayet-Ageron A, Pittet D. Assessing the likelihood of hand-to-hand cross-transmission of Bacteria: an experimental study. Infect Control Hosp Epidemiol. 2017;38(5):553-8. https:// doi.org/10.1017/ice.2017.9.

32. Li L-y, Zhao Y-c, Jia J-x, Zhao X-I, Jia H-x. Investigation on compliance of hand hygiene of healthcare workers. CAMS. 2008;30(5):546-9. https://doi. org/10.3881/j.issn.1000-503X.2008.05.008 URL: http://www.actacams.com/ Jwk_yxkxy/EN/.

33. Al-Wazzan B, Salmeen Y, Al-Amiri E, et al. Hand hygiene practices among nursing staff in public secondary care hospitals in Kuwait: self-report and direct observation. Med Princ Pract. 2011;20:326-31.

34. Omuemu VO, Ogboghodo EO, Opene RA, Oriarewo P, Onibere O. Hand hygiene practices among doctors in a tertiary health facility in southern Nigeria. J Med Trop. 2013;15:96-101 [cited 8 Jan 2017]. Available from: http://www.jmedtropics.org/text.asp?2013/15/2/96/123579. 
35. Abdella, et al. Hand hygiene compliance and associated factors among health care providers in Gondar University Hospital, Gondar, North West Ethiopia. BMC Public Health. 2014;14:96.

36. Marjadi B, MCLaws ML. Hand hygiene in rural Indonesian healthcare workers: barriers beyond sinks, hand rubs and in-service training. J Hosp Infect. 2010;76:256-60.

37. Bukhari SZ, Hussain WM, Banjar A, Almaimani WH, Karima TM, Fatani MI. Hand hygiene compliance rate among healthcare professionals. Saudi Med J. 2011;32(5):515-9.

38. Shobowale EO, Onyedibe KI, Adegunle KB, Elikwu CJ. An observational and trend analysis study of hand hygiene practices of healthcare workers at a private Nigerian Tertiary Hospital. Ann Med Health Sci Res. 2017;7:84-9.

39. Uneke CJ, Ndukwe CD, Oyibo PG, Nwakpu KO, Nnabu RC, Prasopa-Plaizier N. Promotion of hand hygiene strengthening initiative in a Nigerian teaching hospital: implication for improved patient safety in low-income health facilities. Braz J Infect Dis. 2014;18(1):21-7. https://doi.org/10.1016/j.bjid.2013.04.006.

40. Pires D, Pittet D. Hand hygiene mantra: teach, monitor, improve and celebrate. J Hosp Infect. 2017;95(4):335-7. https://doi.org/10.1016/j.jhin.2017.03.009.

41. Doron SI, Kifuji K, Hynes BT, et al. A multifaceted approach to education, observation, and feedback in a successful hand hygiene campaign. Jt Comm J Qual Patient Saf. 2011;37:3-10.

42. Erasmus V, Daha TJ, Brug H, Richardus JH, Behrendt MD, Vos MC, et al. Systematic review of studies on compliance with hand hygiene guidelines in hospital care. Infect Control Hosp Epidemiol. 2010;31:283-94.

43. Ogboghodo EO, Opene RA, Oriarewo P, Onibere O. Hand hygiene practices among doctors in a tertiary health facility in southern Nigeria. J Med Trop. 2013;15:96-101.

44. Pittet D, Mourouga P, Perneger TV, members of the Infection Control Program. Compliance with hand washing in a teaching hospital. Ann Intern Med. 1999;130:126-30

45. Pittet D. Improving adherence to hand hygiene practice: a multidisciplinary approach. Emerg Infect Dis. 2001;7(2):234-40

46. Shehu NY, Bitrus NK. Healthcare environment a war zone. Jos J Med. 2015: 9(2):32.

47. Omuemu V, Ogboghodo EO, Opene RA, Oriarewo P. Hand hygiene practices among doctors in a tertiary health facility in southern Nigeria. J Med Trop. 2013;15(2):96-101 Available from: http://www.ajol.info/index.php/ jmt/article/view/99859.

48. FitzGerald G, Moore G, Wilson APR. Hand hygiene after touching a patient's surroundings: the opportunities most commonly missed. J Hosp Infect. 2013;84(1):27-31. https://doi.org/10.1016/j.jhin.2013.01.00.

49. Shehu NY, Onyedibe Kl, Igbanugo JS, Okolo MO, Gomerep SS, Isa SE, et al. Hand hygiene knowledge, training and practice: a cross-sectional study in a tertiary health institution, North-Central Nigeria. Niger J Clin Pract. 2019;22: 1008-13.

\section{Publisher's Note}

Springer Nature remains neutral with regard to jurisdictional claims in published maps and institutional affiliations.

Ready to submit your research? Choose BMC and benefit from:

- fast, convenient online submission

- thorough peer review by experienced researchers in your field

- rapid publication on acceptance

- support for research data, including large and complex data types

- gold Open Access which fosters wider collaboration and increased citations

- maximum visibility for your research: over $100 \mathrm{M}$ website views per year

At $\mathrm{BMC}$, research is always in progress.

Learn more biomedcentral.com/submissions 